\title{
Inclusão de Armazenamento de Energia para Arbitragem Tarifária
}

\author{
Inclusion of Energy Storage for Time-Shift
}

\author{
Joubert Albuquerque ${ }^{1}$ (D) orcid.org/0000-0003-4432-7737 \\ Pedro André Rosas ${ }^{1,2}$ (iD) orcid.org/0000-0001-9680-7228 \\ 1 Pós-graduação em Energias Solar e Eólica, Escola Politécnica de Pernambuco, Pernambuco, Brasil, \\ 2 Universidade Federal de Pernambuco, Pernambuco, Brasil,
}

E-mail do autor principal: Joubert Albuquerque joubertalbuquerque@gmail.com

\section{Resumo}

Este artigo tem como principal finalidade mostrar algumas diretrizes para a inclusão de técnicas de armazenamento de energia, em alternativa à utilização de geradores a óleo diesel, com o intuito de obter economia nas contas de energia devido à elevada tarifação nos horários de maior carga no sistema elétrico. Uma breve explanação dos equipamentos utilizados para tal finalidade está presente no texto, além de considerações acerca da tarifação de energia elétrica vigente no Brasil. Ao final, verifica-se que, com incentivos governamentais, como diminuição ou isenção de impostos, ou com a queda de custos devido ao desenvolvimento tecnológico dos equipamentos, a inserção dessas técnicas torna-se economicamente viável.

Palavras-Chave: Bateria; Arbitragem; Armazenamento; Energia; Geradores.

\begin{abstract}
The main purpose of this article is to show some guidelines for the inclusion of energy storage techniques, as an alternative to the use of diesel generators, in order to obtain savings in the energy bills due to the high tariffs at the times of greater load in the electrical system. A brief explanation of the equipment used for this purpose is present in the text, as well as considerations about electric energy pricing in force in Brazil. In the end, it can be seen that, with government incentives, such as reduction or exemption from taxes, or with the reduction of costs due to the technological development of the equipment, the insertion of these techniques becomes economically viable.
\end{abstract}

Key-words: Battery; Time-Shift; Storage; Energy; Generators. 


\section{Introdução}

As técnicas de armazenamento já são utilizadas nos sistemas elétricos dos EUA há mais de um século, já que a sua primeira usina hidrelétrica reversível começou a funcionar no ano de 1920 [1]. Esse tipo de tecnologia é utilizado para bombear água que já foi utilizada para girar as turbinas de uma hidrelétrica de volta para o reservatório com o intuito de aumentar a confiabilidade operacional do sistema. Apesar das relativas perdas para tal bombeamento, a utilização desse artifício ainda é viável, pois essa operação pode ser realizada nos horários em que a demanda das cargas é baixa, visto que nesses momentos o custo da energia é muito abaixo dos praticados nos horários de ponta [2].

Observa-se ainda um aumento na demanda por sistemas de armazenamento de energia, principalmente pela grande expansão do mercado das fontes alternativas de energia (solar e eólica), em razão de intermitências no fornecimento de energia nesses tipos de geração. Além disso, a predominância da geração de energia elétrica no Brasil se dá por grandes usinas hidrelétricas, que são totalmente dependentes das chuvas para manterem os níveis de água dos seus reservatórios em valores que garantam a confiabilidade operacional do suprimento das cargas elétricas.

Em consequência disso, no ano de 2015, o Sistema de Bandeiras Tarifárias passou a fazer parte das contas de energia de todos os consumidores cativos que não estão em sistemas isolados, a fim de forçar uma redução no consumo de energia nos períodos em que os reservatórios hídricos estejam em baixa, tornando necessário o acionamento de usinas térmicas, pois as mesmas entram em operação para ajudar a suprir a demanda de carga do sistema[3].

Com a finalidade de reduzir ou até mesmo de eliminar cobranças dessa natureza, buscam-se soluções em tecnologias, tais como a utilização de geradores a óleo diesel ou a inclusão de bancos de baterias, que podem suprir as necessidades energéticas nos horários de ponta e recarregadas nos horários fora de ponta[4][5].

Para que essa tecnologia se torne viável, faz-se necessário o desenvolvimento das variadas formas de armazenar energia, pois alguns métodos disponíveis no mercado ainda possuem empecilhos de natureza técnica, como baixa densidade de energia ou baixa potência, ou de natureza econômica, como o alto custo para a utilização de baterias de íons de Lítio no armazenamento de energia.
O intuito deste artigo é mostrar algumas considerações para a inclusão de sistemas de armazenamento em unidades consumidoras atendidas pelas concessionárias de energia, em alternativa à utilização de geradores a óleo diesel, utilizando o artifício da arbitragem tarifária (timeshift) para diminuir ou até mesmo eliminar o consumo de energia proveniente das concessionárias em horários de ponta, como ilustrado na Figura 1, uma vez que as tarifas energéticas neste horário para algumas classes de clientes são consideravelmente mais elevadas.

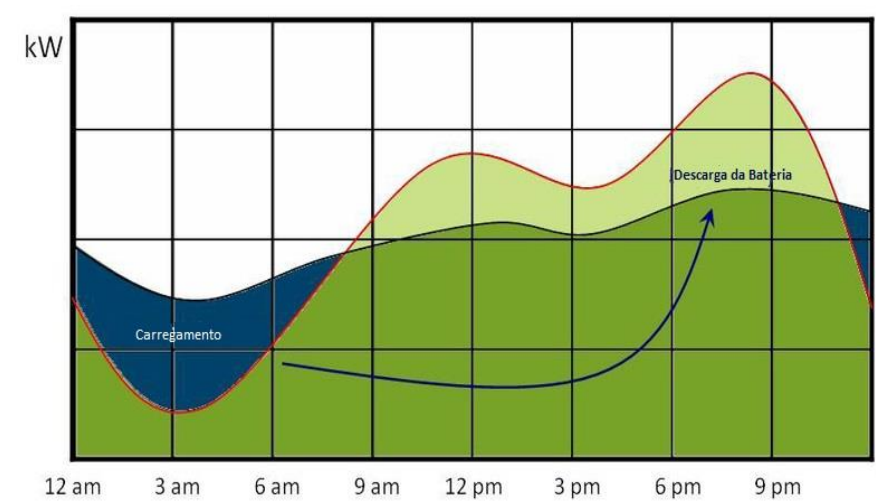

Figura 1: Exemplo de arbitragem.

Fonte: Adaptado de Apollo Solar (s.d.)[6].

\section{Componentes do Sistema}

Para a implementação de um sistema que possa realizar o processo do time-shift, são utilizados equipamentos descritos nos próximos subtópicos.

\subsection{Painéis Fotovoltaicos}

Painéis fotovoltaicos são conjuntos de células fotovoltaicas, compostas pela junção de semicondutores dos tipos " $p$ " e " $n$ ", que apresentam a característica de emitir corrente elétrica a partir da incidência de luz nessas células[7].

Os materiais utilizados na fabricação dessas células têm como base em sua composição o silício que, quando adicionadas "impurezas", aumentam a densidade de corrente obtida através da luz incidente nas placas. Atualmente, os tipos de painéis encontrados no mercado são os monocristalinos, policristalinos e o de película fina[8]. Um exemplo de módulo fotovoltaico pode ser visto na Figura 2. 


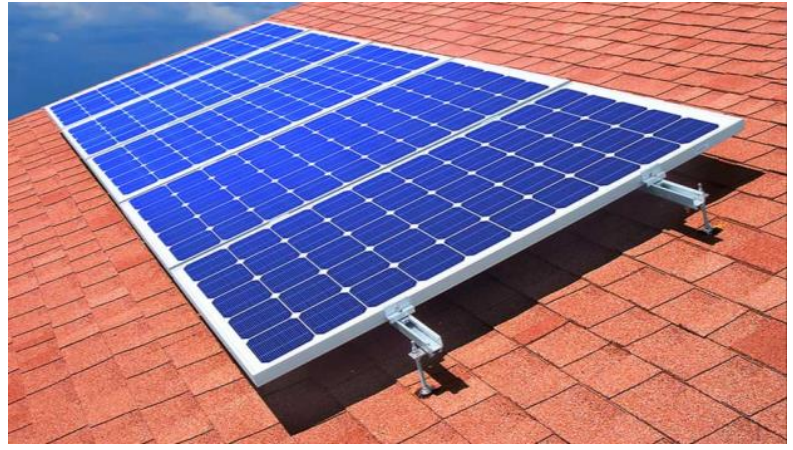

Figura 2: Painéis fotovoltaicos sobre um telhado. Fonte: Portal Solar (s.d.)[9].

\subsection{Baterias}

As baterias são, por definição, um arranjo de elementos onde acontecem reações de oxidorredução, gerando corrente elétrica. Esse elemento básico é conhecido como pilha[10]. Um diagrama esquemático de uma pilha pode ser observado na Figura 3.

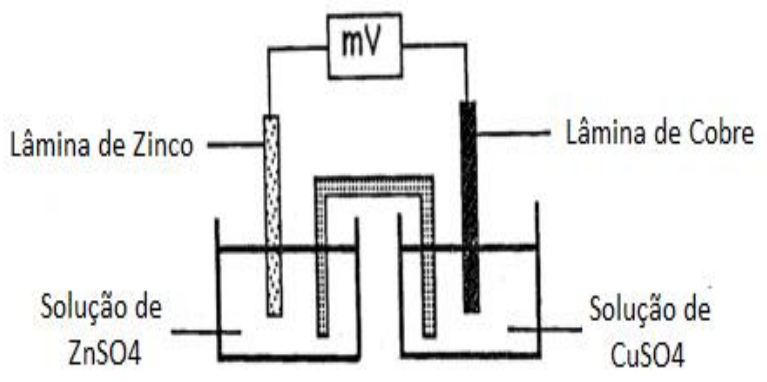

Figura 3: Diagrama esquemático de uma pilha. Fonte: Adaptado de Boulabiar [11].

Existem vários tipos de baterias, tais como as de Níquel-Cádmio, Chumbo-Ácido, Íons de Lítio, baterias de fluxo, entre outras. As tecnologias abordadas neste trabalho são as de $\mathrm{PbC}$ e de íons de Lítio, pois são as que possuem as características mais adequadas para a o emprego em time-shift.

As características elétricas mais importantes a serem consideradas em projetos envolvendo baterias são[1]:
- Potência;
- Energia;
- Tempo de resposta;
- Duração de descarga;
- Profundidade de descarga;
- Frequência de descarga;
- Eficiência.

Além disso, deve-se levar em consideração a temperatura do ambiente de operação e a disponibilidade espacial do empreendimento, pois a maioria das tecnologias possuem uma baixa densidade de energia (dimensões na Figura), como pode ser visto na Figura 4.

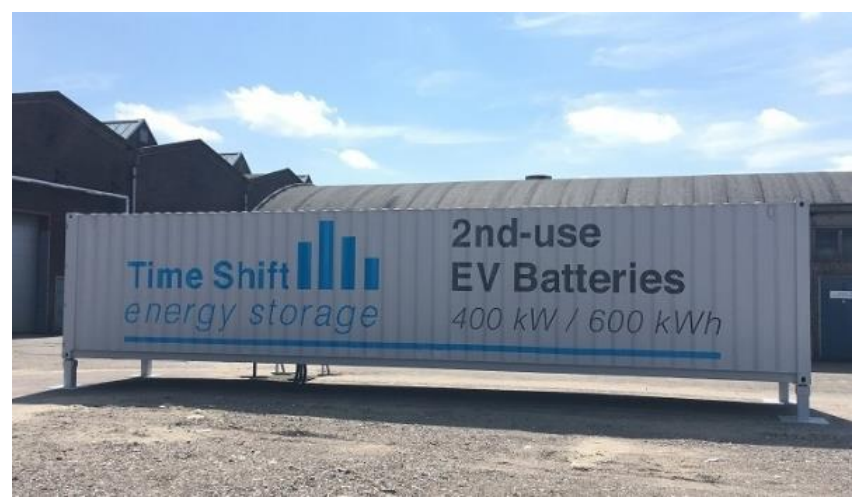

Figura 4: Banco de baterias em uma instalação. Fonte: Smart Storage(s.d.)[12].

\subsection{Inversores}

Os equipamentos elétricos alimentados por sistemas dessa natureza, que são os equipamentos encontrados nos âmbitos residenciais, comerciais e industriais, são produzidos para serem alimentados em corrente alternada. Porém, a natureza da energia obtida nos processos eletroquímicos e fotoelétricos (painéis fotovoltaicos) são de corrente contínua. Para que seja possível utilizar a energia proveniente de baterias e módulos fotovoltaicos, é necessário um equipamento que realize a conversão $C C / C A$, que é exercida por um inversor de frequência. Um exemplo de inversor de frequência comercial pode ser visto na Figura 5. 


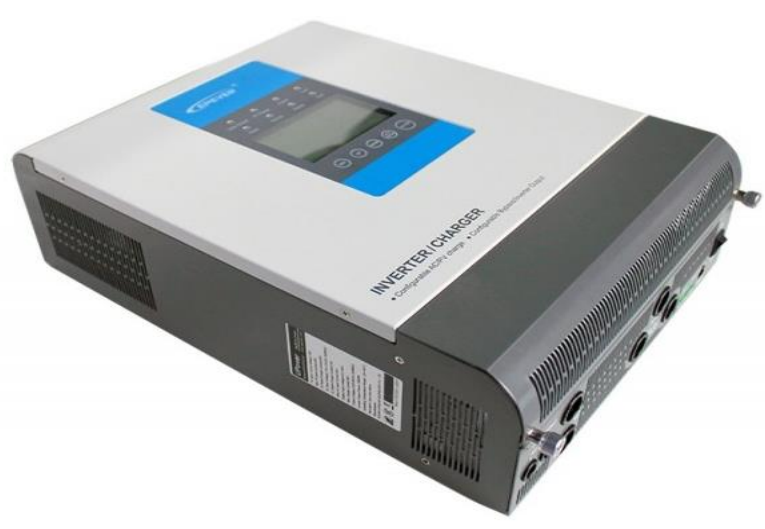

Figura 5: Inversor de frequência comercial. Fonte: Neosolar (s.d.)[13].

\subsection{Controladores de Carga}

Controladores de carga são os equipamentos responsáveis pelo controle de fluxo de corrente nas baterias, protegendo-as contra as cargas e descargas excessivas. Esses controladores têm a capacidade de desconectar o banco de baterias quando estas se encontram em situações que podem causar danos irreversíveis à saúde das baterias, incluindo aumentos abruptos na corrente em seus terminais[14]. Um controlador de carga comercial pode ser visto na Figura 6.

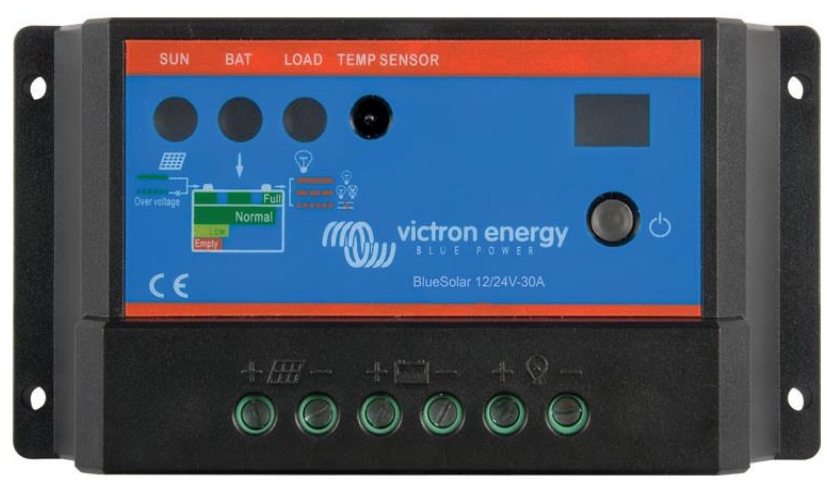

Figura 6: Controlador de Carga comercial. Fonte: Aldo Solar (s.d.)[15].

\section{Metodologia}

Da mesma forma que acontece em qualquer aplicação comercial de engenharia, a viabilidade técnica não é suficiente para a tomada de decisão para implementação dos sistemas de armazenamento de energia. Deve-se levar em consideração, principalmente, as questões de custo/benefício.
Dessa forma, é essencial a análise de questões econômicas consideradas ao projetar sistemas dessa natureza, além de diretrizes para o dimensionamento do armazenamento de energia.

\subsection{Tipos de Carga}

No Brasil, os consumidores de energia elétrica estão divididos de acordo com as suas classes e subclasses de consumo, em conformidade com a Resolução Normativa ANEEL no 414/2010 [16]. As classes e subclasses estão especificadas abaixo:

\section{Residencial}

- Residencial baixa renda;

- Residencial baixa renda Indígena;

- Residencial baixa renda benefício de prestação continuada da assistência social;

- Residencial baixa renda multifamiliar.

\section{Comercial}

- Serviços de transporte, exceto tração elétrica;

- Serviços de comunicações e telecomunicações;

- Associação e entidades filantrópicas;

- Templos religiosos;

- Administração condominial: iluminação e instalações de uso comum de prédio ou conjunto de edificações;

- Iluminação em rodovias: solicitada por quem detenha concessão ou autorização para administração em rodovias;

- Semáforos, radares e câmeras de monitoramento de trânsito, solicitados por quem detenha concessão ou autorização para controle de trânsito.

\section{Industrial}

- Todos os clientes com atividades industriais, exceto os pertencentes ao agroindustrial.

\section{Rural}

- agropecuária rural; 
- instalações elétricas de poços de captação de água

- serviço de bombeamento de água destinada à atividade de irrigação.

- agropecuária urbana:

- residencial rural;

- cooperativa de eletrificação rural;

- agroindustrial;

- serviço público de irrigação rural;

- escola agrotécnica: estabelecimento de ensino direcionado à agropecuária;

- aquicultura.

\section{Poder Público}

- Iluminação Pública;

- Serviço Público:

- tração elétrica;

- água, esgoto e saneamento;

- Consumo Próprio.

\subsection{Tarifação de Energia}

No Brasil, as modalidades tarifárias estão subdivididas em dois grandes grupos, determinados pelo nível de tensão em que a concessionária entrega a energia às unidades consumidoras, com as classes de consumo e conforme a atividade desempenhada na unidade consumidora[14][17].

\section{Grupo A}

O grupo A corresponde aos clientes que recebem energia elétrica com tensão maior ou igual a $2.3 \mathrm{kV}$, exceto os que são alimentados por redes subterrâneas[14]. Além disso, tem-se a subdivisão desse grupo como a seguir:

- A1 - tensão de fornecimento igual ou superior a $230 \mathrm{kV}$;

- A2 - tensão de fornecimento de $88 \mathrm{kV}$ a $138 \mathrm{kV}$;

- A3 - tensão de fornecimento de $69 \mathrm{kV}$;

- A3a - tensão de fornecimento de $30 \mathrm{kV}$ a $44 \mathrm{kV}$;

- A4 - tensão de fornecimento de $2,3 \mathrm{kV}$ a $25 \mathrm{kV}$;

- AS - tensão de fornecimento inferior a $2,3 \mathrm{kV}$, por meio de sistema subterrâneo de distribuição.
Para o grupo em questão, existem três modalidades tarifárias, podendo ser escolhidas pelo cliente, de acordo com suas necessidades e vantagens econômicas. As três modalidades estão definidas a seguir[17]:

- Azul - caracteriza-se por tarifas de consumo e demanda de consumo, conforme utilização horária;

- Verde - semelhante à modalidade azul em relação à tarifa de consumo, porém com tarifa única para demanda de potência;

- Convencional Binômia - Essa modalidade possui as tarifas independentes do horário de utilização ao longo do dia, tanto para consumo de energia quanto para demanda de potência. É uma tarifa que saiu de operação no ano de 2018 no estado de Pernambuco.

\section{Grupo B}

O grupo B corresponde aos clientes que recebem energia elétrica a um nível de tensão que não ultrapasse $2,3 \mathrm{kV}$, exceto os que são alimentados por meio de instalações subterrâneas[14], subdivididos em:

- B1 - residencial;

- B2 - rural;

- B3 - demais classes;

- B4 - Iluminação Pública.

Para este grupo, existem apenas duas opções de modalidades tarifárias que também podem ser escolhidas pelo cliente, em função de suas necessidades[17]. As duas modalidades são definidas como:

- Convencional Monômia - caracteriza-se por tarifas única de consumo, independente do horário de uso da energia;

- Branca - Aplica-se aos consumidores desse grupo, com exceções para os clientes incluídos na subclasse Baixa Renda e Subgrupo B4.

A tarifa branca possui três valores diferentes, chamado de ponta, intermediário e fora de ponta, que são contabilizadas de acordo com horários pré-definidos pela concessionária[17]. 


\subsection{Determinação Armazenamento}

Para a determinação do sistema de armazenamento a ser projetado, deve-se verificar, a priori, se a unidade consumidora está enquadrada em uma das modalidades tarifárias que possui tarifas dependentes do horário de utilização (tarifas verde, azul e branca), já que o método consiste no carregamento dos bancos de baterias em momentos de tarifas mais baratas, para que estas supram as cargas nos horários de tarifas mais caras.

Além disso, o perfil de carga da unidade consumidora de energia deve ser analisado, com a finalidade de verificar se há um consumo expressivo de energia nos horários de tarifas mais caras. Devese, também, realizar um levantamento dos equipamentos que serão alimentados pelas baterias. Como o propósito do trabalho é reduzir ou, preferencialmente, eliminar o consumo de energia advinda da concessionária nos horários de ponta, não é necessário incluir os equipamentos que serão alimentados apenas nos horários fora de ponta.

As tecnologias de armazenamento devem ser escolhidas de acordo com o tipo de aplicação as quais estarão submetidas, visto que existem várias delas no mercado e cada uma mostra-se mais apropriada para determinadas finalidades. Por exemplo, para a supressão de flutuações na rede, as descargas de uma bateria seriam frequentes, porém curtas; já para suprir a intermitência de uma planta solar fotovoltaica, as descargas seriam longas, mas com menor frequência[1]. Diante disso, a utilização de baterias de íons de lítio, para o primeiro exemplo, poderia ser mais viável tecnicamente do que baterias de NiCd.

Em aspectos econômicos, verifica-se que normalmente as tecnologias possuem bons custos teóricos para aplicações de potência ou de energia, mas não para ambos simultaneamente, como pode ser verificado na Figura 7[18].
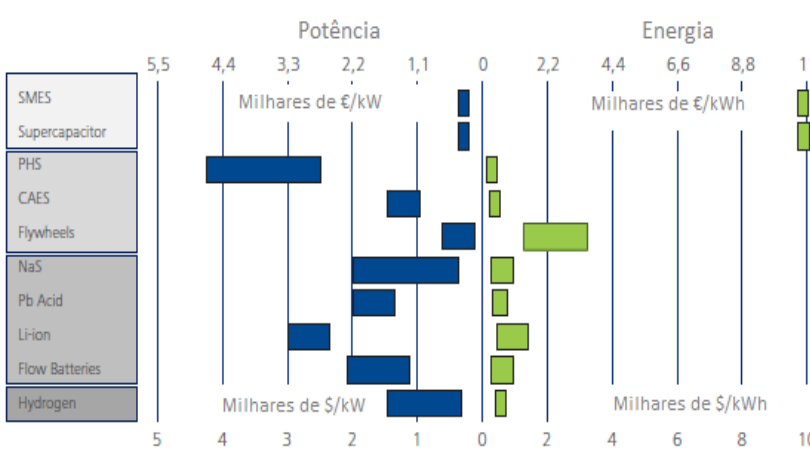

Figura 7: Custos para tecnologias de armazenamento. Fonte: Adaptado de De La Rubia et al (2015)[18].

A vida útil desse tipo de sistema depende fortemente da profundidade de descarga as quais serão submetidas. Baterias de íons de lítio podem sofrer descargas de até $90 \%$ sem apresentar maiores problemas, porém projetos que utilizam chumbo ácido devem ser dimensionados para uma profundidade máxima de descarga de $50 \%$. É imprescindível que a lógica do controlador de cargas retire de operação o banco de baterias quando o nível mínimo é atingido.

O carregamento das baterias pode ser realizado utilizando apenas a energia proveniente da concessionária em horários fora de ponta, como também com o auxílio de um sistema fotovoltaico (parte tracejada da Figura 8), a depender da viabilidade técnico-financeira do projeto.

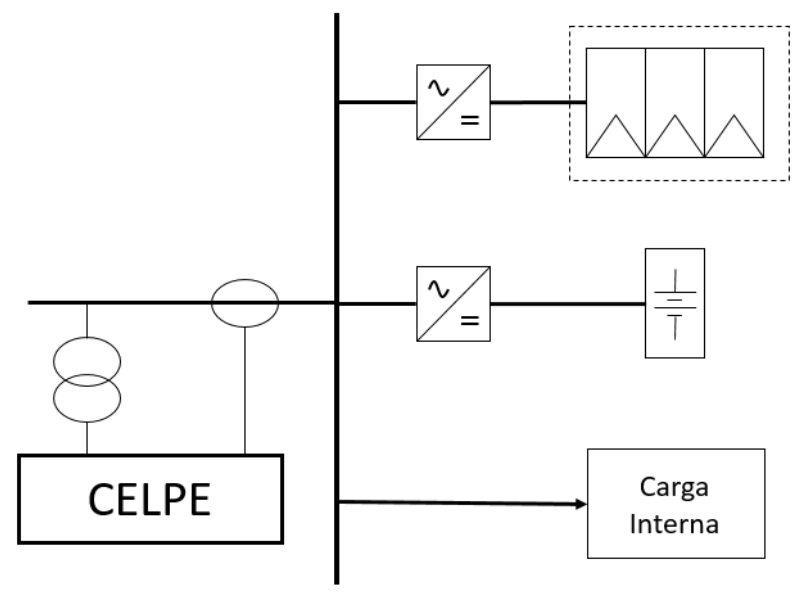

Figura 8: Diagrama do sistema proposto. Fonte: $O$ autor.

O sistema proposto (Figura 8), funciona da seguinte forma: o banco de baterias é recarregado pela energia proveniente da concessionária em horários que a tarifa de energia é mais barata (fora de ponta) e/ou por um conjunto de painéis fotovoltaicos acoplados ao 
barramento do cliente, para serem descarregadas nos horários de tarifas de energia mais caras (ponta).

\section{Estudo de Caso}

Diante das definições sobre os aspectos técnicos e econômicos acerca da inserção de sistemas de armazenamento de energia acima citados, realizou-se um estudo de caso a fim de obter resultados para a tomada de decisão em projetos desse tipo.

O objeto de estudo é uma instituição de ensino superior localizada na cidade de Recife/PE, alimentada em 13,8 kV, pertencente ao grupo A4 (comercial), optante pela tarifa verde. O perfil de consumo na ponta e fora de ponta do cliente foi retirado das últimas 12 faturas e pode ser visto na Figura 9. Verifica-se uma grande diminuição do consumo de energia nos meses de janeiro, junho, julho e dezembro, devido às férias dos setores de aula, mas com a manutenção de parte dos serviços administrativos durante esse período.

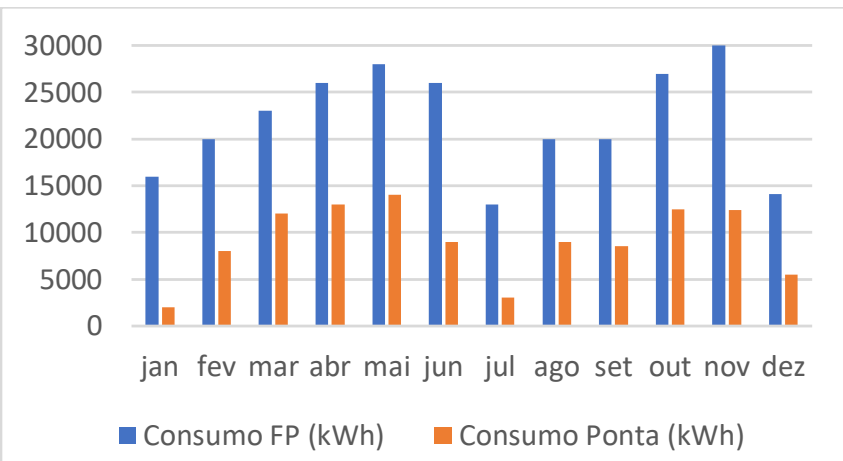

Figura 9: Perfil de carga do cliente.

Fonte: $\mathrm{O}$ autor.

Para este caso, foi determinado um sistema de armazenamento para suprir toda a carga no horário de ponta, a partir do consumo baseado no pior caso mensal, sendo registrado $14.000 \mathrm{kWh}$ no mês de maio do corrente ano. O consumo diário na ponta foi obtido dividindo-se esse valor pela quantidade de dias contabilizados com distinção de tarifas, que foram 23 dias para o mês em questão, em 3 horas de operação diária, obtendo-se 610 kWh/dia.

Como a profundidade máxima de descarga para um sistema utilizando baterias de íons de lítio é de $90 \%$ sem que esta sofra maiores danos, a capacidade do sistema foi aumentada para $673 \mathrm{kWh}$. Apesar disso, o sistema ainda sofre uma redução sua capacidade de armazenamento, chegando a $70 \%$ ao final de 15 anos de uso. Portanto, a capacidade inicial do sistema foi definida como $961 \mathrm{kWh}$ [19]. A eficiência da carga e descarga decai de $93 \%$ para $86 \%$ no período de 15 anos, mas foi negligenciada na elaboração deste estudo de caso[19].

Após a determinação da capacidade de armazenamento das baterias, uma tabela foi elaborada com os valores referentes às contas de energia com e sem o sistema, obtendo-se economias mensais individuais do empreendimento, com o intuito de se obter a base de economia anual para este empreendimento. Esses dados podem ser verificados na Figura 10. Os valores utilizados para essa contabilização foi de 0,37 R $\$ / k W h$ e 2,01 $\mathrm{R} \$ / \mathrm{kWh}$ para fora ponta e ponta, respectivamente[19].

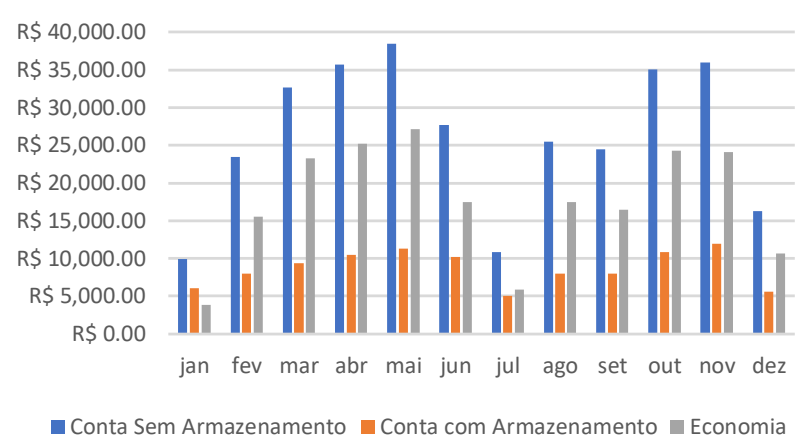

Figura 10: Gráfico de economia mensal do sistema. Fonte: $\mathrm{O}$ autor.

A economia anual foi obtida através do somatório das economias mensais. Foi definido um aumento nas contas de energia de $5 \%$, que é um valor médio de inflação anual. As economias anuais ao longo da vida útil do sistema podem ser vistas na Figura 11.

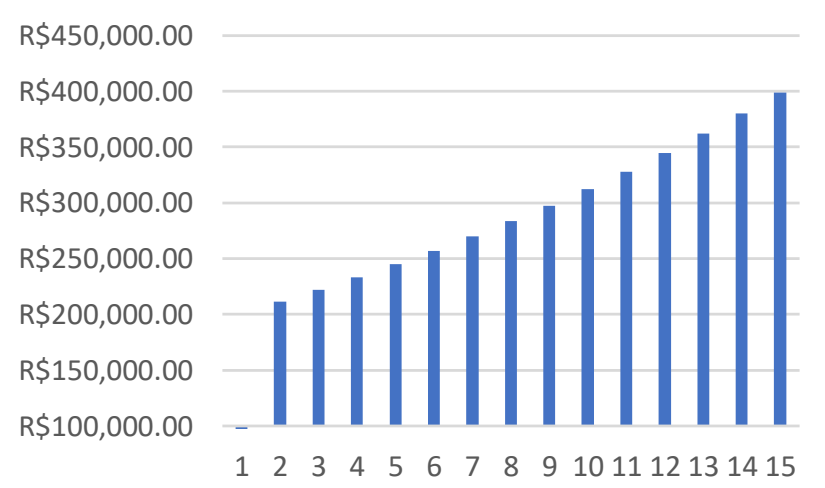

Figura 11: Gráfico de economia anual durante vida útil do sistema.

Fonte: $\mathrm{O}$ autor. 
A definição do custo do sistema é algo que merece uma certa atenção, pois não foi possível encontrar fornecedores nacionais para os equipamentos. Segundo Fu et al, o preço das baterias de íons de lítio são de 209 US\$/kWh[20], mas também devem ser considerados custos com todos os outros equipamentos envolvidos no funcionamento. De acordo com Hoff e Lin, o custo de um sistema desse tipo é de $450 \mathrm{US} \$ / \mathrm{kWh}$ [21], sendo este o valor utilizado no trabalho, obtendo-se um custo inicial de R\$1.661.351,04 em conversão direta, com o dólar cotado a $\mathrm{R} \$ 3,84$ na data da elaboração do estudo.

Assim como a maioria dos equipamentos importados para o Brasil, impostos e contribuições federais são contabilizados e aplicados aos produtos que compõem o sistema de armazenamento, chegando a aproximadamente $40 \%$ do valor de conversão direta do que foi pago na aquisição equipamentos. Além disso, há incidência de imposto estadual sobre esses produtos (ICMS), que varia para cada estado onde será aplicado[19]. O valor do ICMS para o estado de Pernambuco está cotado em $17 \%$ do valor total, após a contribuição federal. Este último imposto foi desconsiderado nos cálculos e foi obtido um custo de $\mathrm{R} \$ 2.325 .888,00$ para a obtenção dos equipamentos.

Os custos operacionais anuais foram determinados a partir de taxas definidas por Hoff e Lin. O somatório desses custos resulta em 3,6\% do investimento inicial. Também incidiu um aumento anual de $5 \%$ nos valores anuais destes serviços, por se tratar de um equipamento com média vida útil[21].

Após a inclusão de todos esses dados na planilha, realizou-se uma análise viabilidade financeira baseada nos resultados obtidos. Foram considerados dois cenários para esta avaliação. No primeiro cenário, considerou-se o sistema com todos os impostos incidentes sobre a aquisição dos equipamentos. Já no segundo caso, levou-se em consideração apenas o valor de aquisição em conversão direta. Os custos operacionais estão presentes em ambas as análises. Os fluxos de caixa baseados em valores presentes acumulados dos dois casos podem ser observados na Figura 12.

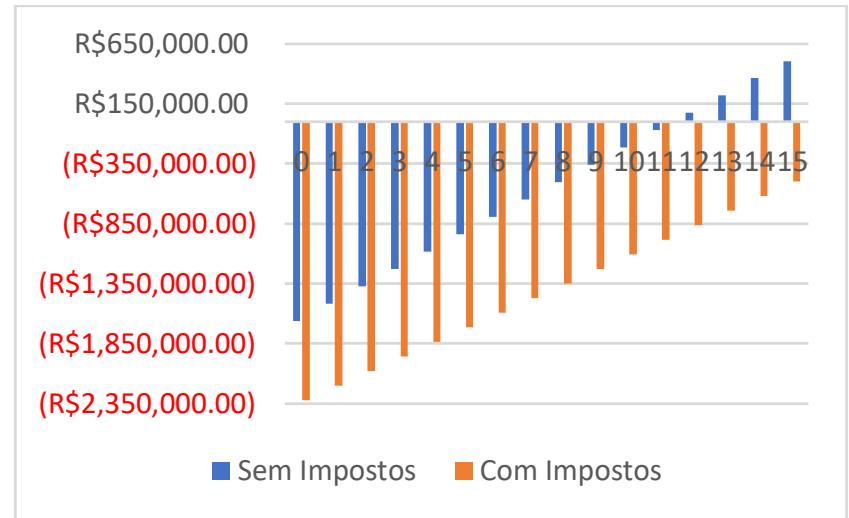

Figura 12: Fluxos de caixa anuais acumulados do cliente com o sistema.

Fonte: O autor.

Verifica-se, então, que para o caso sem impostos, o VPL foi de $\mathrm{R} \$ 505.222,99$, com uma taxa interna de retorno de $8,69 \%$ e tempo de payback de aproximadamente 11 anos e meio, viável por ter uma vida útil de 15 anos. Já para a segunda situação, o VPL foi de $\mathrm{R} \$-501.079,57$, com uma taxa de retorno de $1,97 \%$, inviável por não se pagar ao longo de sua operação.

\section{Conclusões}

O presente trabalho científico evidenciou, através de um estudo, a viabilidade econômica e técnica da inserção de um sistema de baterias, com a finalidade de armazenar energia em horários fora de ponta para ser utilizada em horários de ponta, em alternativa ao uso de geradores a óleo diesel em unidades consumidoras inseridas no grupo $A$.

Para chegar aos resultados, foi analisado qual seria o método de armazenar energia mais adequado para este fim, que é o de íons de lítio que, apesar do custo elevado, possuem características elétricas mais apropriadas para o uso em time-shift. Ainda, foram citados equipamentos auxiliares para que seja possível o funcionamento dessas baterias em conjunto com a carga. Além disso, verificou-se que as cargas elegíveis para este processo são as constantes nas tarifas azul, verde ou branca, de acordo com a resolução $N^{\circ} 414 / 2010$ da ANEEL. Tais dados foram determinantes para a elaboração do estudo de caso deste trabalho.

Com o estudo de caso, foi possível verificar que sistemas desse tipo só seriam viáveis economicamente nos dias atuais com a redução ou isenção de impostos federais e estaduais para a aquisição dos equipamentos ou com seu barateamento a partir do desenvolvimento tecnológico das variadas técnicas de armazenamento, podendo ser utilizadas, também, em conjunto com geração de energia solar fotovoltaica. 
Apesar de ainda não ser viável economicamente hoje, o uso dessa tecnologia poderá impactar direto ou indiretamente na sociedade, pois os serviços e produtos advindos de indústrias e comércios que são tarifados de acordo com o horário de uso são repassados ao consumidor final.

\section{Referências}

[1] CARNEGIE, R. et al. Utility scale energy storage systems. State Utility Forecasting Group. Purdue University, v. 1 . Disponível em: < https://www.purdue.edu/discoverypark/sufg/docs/p ublications/SUFG\%20Energy\%20Storage\%20Report. pdf > Acesso em: 10 jul. 2019.

[2] ZUCULIN, S.; PINTO, M.; BARBOSA, P. S. F. A Retomada do Conceito de Usinas Hidrelétricas Reversíveis no Setor Elétrico Brasileiro. Seminário Eletronorte, 2014.

[3] ANEEL. Bandeiras Tarifárias - Tarifas Consumidores - ANEEL. Disponível em: <http://www.aneel.gov.br/tarifas-consumidores//asset_publisher/e2INtBH4EC4e/content/bandeiratarifaria/654800? inheritRedirect $=$ false $>$. Acesso em: 25 jan. 2019.

[4] PEREIRA, R. H. et al. Geração Distribuída de Energia Elétrica-Aplicação de Motores Bicombustível Diesel/Gás Natural. $3^{\circ}$ Congresso Brasileiro de P\&D em Petróleo e Gás, Salvador, p. 25, 2005.

[5] MASSERONI, J.; OLIVEIRA, C. M. DE. Utilização de grupos geradores diesel em horário de ponta. Revista Modelos-FACOS/CNEC, v. 2, n. 2, p. 5256, 2012.

[6] SOLAR, A. Hybrid Solar PV Systems and off grid solutions now available from Apollo Solar. Disponível em: <http://apollotsv.com.au/hybridsolar-systems-off-grid>. Acesso em: 27 jun. 2019.

[7] PRIEB, C. W. M. Desenvolvimento de um sistema de ensaio de módulos fotovoltaicos. 2002. Dissertação de Mestrado.
Produção entre Centrais Fotovoltaicas de Silício Policristalino e Amorfo, 2016.

[9] SOLAR, P. Folha de Dados do Painel Solar o Que Você Precisa Saber. Disponível em: $<$ https://www.portalsolar.com.br/folha-de-dadosdo-painel-solar---o-que-voce-precisa-saber.html>. Acesso em: 27 jun. 2019.

[10] DIOGO LOPES DIAS. Baterias. Disponível em: $<$ https://www.manualdaquimica.com/fisicoquimica/baterias.htm>. Acesso em: 28 may. 2019.

[11] BOULABIAR, A. et al. A historical analysis of the Daniell cell and electrochemistry teaching in French and Tunisian textbooks. Journal of Chemical Education, v. 81, n. 5, p. 754, 2004.

[12] STORAGE, S. Time Shift Energy Storage wint Jan Terlouw Innovatieprijs 2018. Disponível em:

$<$ https://smartstoragemagazine.nl/nieuws/i16908/ti me-shift-energy-storage-wint-jan-terlouwinnovatieprijs-2018>. Acesso em: 27 jun. 2019.

[13] NEOSOLAR. Inversor Híbrido Epever Upower 3000W / 30A MPPT / 24Vcc / 220Vca. Disponível em: $<$ https://www.neosolar.com.br/loja/inversorhibrido-epever-upower-up3000-30a-24vcc220vca.html>.

[14] CUNHA, L. C. C. DA. PROPOSTA DE MITIGAÇÃO DOS IMPACTOS TÉCNICOS E FINANCEIROS ORIUNDOS DE SISTEMAS FOTOVOLTAICOS NA GERAÇÃO DISTRIBUÍDA PARA AS DISTRIBUIDORAS DE ENERGIA. p. 106, 2018. Monografia. Universidade Federal de Pernambuco.

[15] SOLAR, A. Controlador Carga Bateria Solar Victron Aldo Solar. Disponível em: <https://www.aldo.com.br/Produto/?c=33424\&d=co ntrolador-carga-bateria-solar-victron-aldo-solarSCC010030020>.

[16] AGÊNCIA NACIONAL DE ENERGIA ELÉTRICA. RESOLUÇÃO NORMATIVA N ${ }^{\circ} 414$. Resolução Normativa n 414, 2010.

[17] ANEEL. Modalidades Tarifárias. Disponível em: consumidores/-
$<$ http://www.aneel.gov.br/tarifas- 
/asset_publisher/zNaRBjCLDgbE/content/modalidade /654800?inheritRedirect=false $>$. Acesso em: 5 jun. 2019.

[18] DE LA RUBIA, T. Diaz et al. Tracking the Technologies that will Transform the Power Sector. New York City: Delloite, 2015.

[19] THOMÉ, M. H. C. ANÁLISE DE VIABILIDADE ECONÔMICA DA IMPLANTAÇÃO DE SISTEMAS DE BATERIAS DE LÍTIO-ÍON EM UNIDADES CONSUMIDORAS CONECTADAS NA MÉDIA TENSÃO. 2017. Tese de Doutorado. Universidade Federal do Rio de Janeiro.

[20] FU, R.; REMO, T. W.; MARGOLIS, R. M. 2018 US Utility-Scale Photovoltaics-Plus-Energy Storage System Costs Benchmark. National Renewable Energy Lab.(NREL), Golden, CO (United States), 2018.

[21] HOFF, C. M.; LIN, R. Development and practical use of a levelized cost of storage (LCOS) metric. Westborough: NEC Energy Solutions, 2016. 